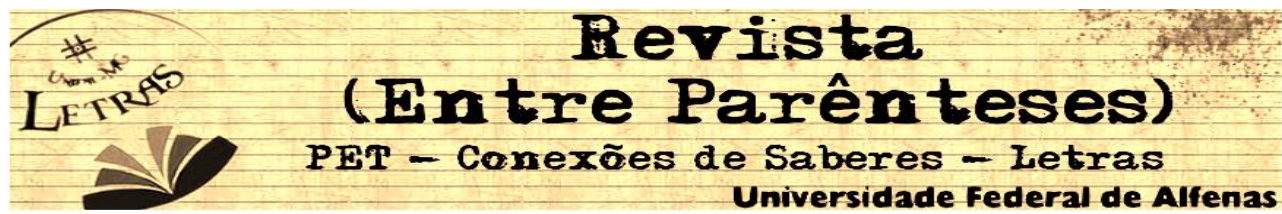

\title{
O ENTRE-LUGAR MACHADIANO: FORMAÇÃO DE UMA LITERATURA NACIONAL
}

\author{
Ionara Satin 1 \\ Universidade Estadual Paulista Júlio de Mesquita Filho \\ (ionarasatin@gmail.com)
}

\begin{abstract}
RESUMO: O objetivo desse artigo é demonstrar como o termo entre-lugar cunhado por Silviano Santiago em seu texto "O entre-lugar do discurso latino-americano" aplica-se a proposta de Machado de Assis quando ele trata da situação da literatura brasileira em seu famoso ensaio "Notícia da atual literatura brasileira: instinto de nacionalidade", de 1873, no qual propõe um outro lugar para a literatura produzida no Brasil naquela época, uma saída, que neste estudo será abordado como entre-lugar. Silviano Santiago desloca o discurso literário latino-americano para um entre-lugar, colocando a América Latina em evidência e essa também parece ser a proposta de Machado de Assis para a independência da literatura brasileira já naquela época. Esse texto machadiano parece funcionar como uma carta programa para uma literatura independente, uma proposta para marcar o lugar da literatura brasileira, longe de doutrinas absolutas que a embopreçam e longe das amarras europeias. Isto é, um entre-lugar, que não está nem na figura do índio e tampouco na imitação dos modelos europeus.
\end{abstract}

PALAVRAS-CHAVE: Literatura nacional, Machado de Assis, Silviano Santiago.

\begin{abstract}
The purpose of this article is to demonstrate how the term entre-lugar by Silviano Santiago in his text "O entre-lugar do discurso latino-americano" applies to proposed Machado when he deals with the situation of Brazilian literature in his famous essay "Notícia da atual literatura brasileira: instinto de nacionalidade" of 1873, which proposes another place for literature produced in Brazil at that time, a way out, that this study will be covered as in entre-lugar. Silviano Santiago shifts the Latin American literary discourse to an in entre-lugar, placing Latin America in evidence and this also seems to be the proposal of Machado de Assis for the independence of Brazilian literature even then. This Machadian text seems to work as a letter program for an independent literature, a proposal to mark the place of Brazilian literature, distant to absolute doctrines that impoverish and away from European bonds. That is, an "entre-lugar", which is neither in the Indian figure nor in imitation of European models.
\end{abstract}

KEYWORDS: National literature; Machado de Assis, Silviano Santiago.

\section{INTRODUÇÃO}

Em 1971, Silviano Santiago publica o texto "O entre-lugar do discurso latinoamericano" em seu livro Uma literatura nos trópicos: ensaios sobre dependência

\footnotetext{
${ }^{1}$ Graduada em Letras pela Universidade Estadual Paulista Júlio de Mesquita Filho - Faculdade de Ciências e Letras de Assis, com intercâmbio de estudos na Università degli Studi di Perugia. Desenvolveu pesquisa de Iniciação Científica financiada pela FAPESP. Mestrado em Letras pela Universidade Estadual Paulista Júlio de Mesquita Filho - FCL-UNESP/Assis, financiada pela Capes. Atualmente é doutoranda do programa de pós-graduação em Letras pela mesma Universidade com pesquisa financiada pela FAPESP.
} 


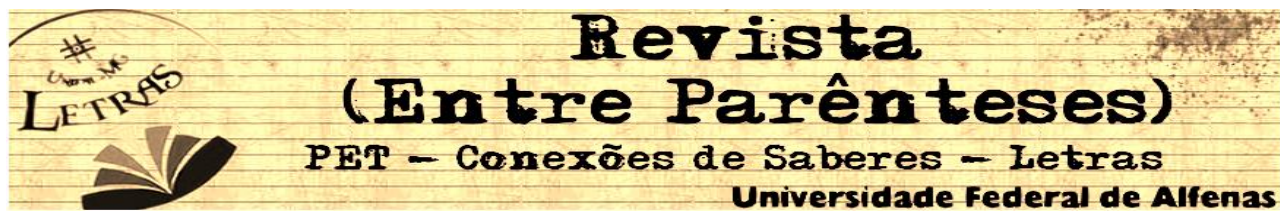

cultural, no qual aponta uma inversão de valores do discurso literário latinoamericano no confronto com o europeu. Silviano questiona o próprio conceito de superioridade, aponta que a maior contribuição da America Latina para a cultura ocidental vem da destruição dos conceitos de unidade e de pureza: "estes dois conceitos perdem o contorno exato de seu significado, perdem seu peso esmagador, seu sinal de superioridade cultural, à medida que o trabalho de contaminação dos latino-americanos se afirma, se mostra mais e mais eficaz." (SANTIAGO, 2000, p.16).

Santiago critica as pesquisas que conduzem aos estudos das fontes e das influências. Para ele, tal discurso reduz a criação artística latino-americana à condição de obra parasita, obra invisível. Santiago aponta que a originalidade do discurso latino-americano está na ruptura entre o modelo e sua cópia, na digestão que o escritor faz de suas leituras, em transgredir a prisão que o fazia refém do discurso dos colonizadores, esse é lugar do discurso latino-americano, um entrelugar:

Entre o sacrifício e o jogo, entre a prisão e transgressão, entre a submissão ao código e agressão, entre a obediência e a rebelião, entre a assimilação e a expressão - ali, nesse lugar aparentemente vazio, seu templo e seu lugar de clandestinidade, ali, se realiza o ritual antropofágico da literatura latino-americana. (SANTIAGO, 2000, p.26)

Santiago desloca o discurso literário latino-americano para um entre-lugar, colocando a América Latina em evidência. Para ele o valor crítico do discurso literário latino-americano está na diferença e não na cópia, "na assimilação inquieta e insubordinada, antropófaga". (SANTIAGO, 2000, p.20).

Muitos anos antes, ainda em 1873, Machado de Assis procurava outra alternativa para pensar a literatura brasileira da época, escreve então o famoso ensaio "Notícia da atual literatura brasileira: instinto de nacionalidade" e o termo teoricamente cunhado por Santiago parece expressar a alternativa proposta pelo escritor de Dom Casmurro. Isto é, Machado propõe um outro lugar para a literatura produzida no Brasil naquela época, um lugar próprio, um entre-lugar, que não está 


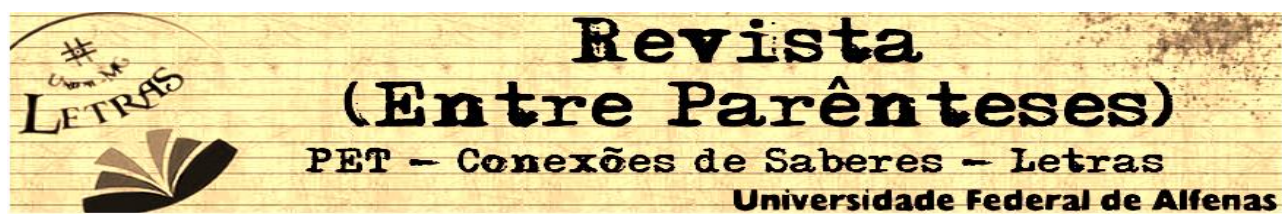

nem na figura do índio e tampouco na imitação dos modelos europeus. Nesse sentido, de que maneira é possível adotar o termo de Silviano Santiago para compreensão do ensaio de Machado de Assis? Teria já o escritor machadiano as mesmas concepções de Silviano Santiago? Qual é a relação de dois textos escritos em épocas tão diferentes?

Antes de responder a todas essas questões, vale pontuar que a ideia de imbricar o termo entre-lugar dentro do espaço do ensaio machadiano vem de dois pontos fundamentais no texto: do contexto de publicação e das diretrizes que percorrem o ensaio. Passemos, a princípio, ao contexto de publicação.

\section{Do Brasil para os Estados Unidos: fora da Europa, entre Américas}

O ensaio machadiano é objeto de estudo de várias pesquisas, porém, muitos trabalhos não se referem ao seu local de publicação, algo que pode acarretar em uma nova perspectiva de interpretação. Nova lorque é a cidade na qual Machado de Assis publica seu ensaio, em um jornal de língua portuguesa, intitulado $O$ Novo Mundo, fundado por José Carlos Rodrigues, entre 1870 e 1879, para distribuição e circulação no Brasil. Publicar nos Estados Unidos um texto a respeito da situação da literatura brasileira é algo que deve ser analisado.

O texto machadiano fez parte do número trinta e foi republicado na edição comemorativa de centésimo número. A partir desses dados, pode-se notar que $O$ Novo Mundo não foi um jornal efêmero. A prática de se editar fora do Brasil não é novidade do jornal de José Carlos Rodrigues, muitos jornais brasileiros foram editados na França, como é o caso da revista Niterói lançada em Paris no ano de 1836. Nesse sentido, aquilo que causa certa estranheza em relação ao jornal de José Carlos Rodrigues é o desvio de olhar da Europa para os Estados Unidos.

A pesquisadora Mônica Maria Rinaldi Asciutti escreveu sobre esse jornal em sua dissertação de mestrado intitulada, Um lugar para o periódico O Novo Mundo (1870 e 1876). Em seu trabalho, Mônica aponta que a França se tornava um modelo preferencial em 1830, período no qual o Brasil era um país recém-independente, preocupado em distanciar-se das marcas coloniais. Já os Estados Unidos pós- 


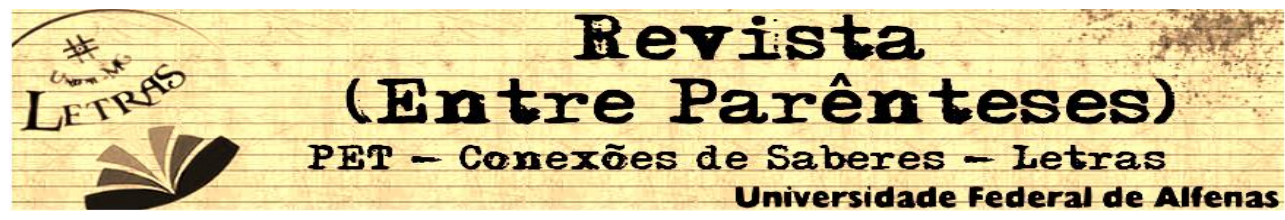

abolição emergiam como a primeira grande potência econômica do continente americano, algo que traz um significado a inserção do jornal O Novo Mundo em solo americano.

José Carlos Rodrigues também era um entusiasta do progresso material e grande admirador dos Estados Unidos "insistia na ideia de que o Brasil deveria seguir o modelo de desenvolvimento estadunidense" (ASCIUTTI, p.12). O jornal tinha como objetivo apresentar aos seus patrícios as novidades e o desenvolvimento daquele país, daí o subtítulo "Periódico llustrado do Progresso e da Edade".

FIGURA 1- Página de abertura do primeiro número do periódico O Novo Mundo, de outubro de 1870.

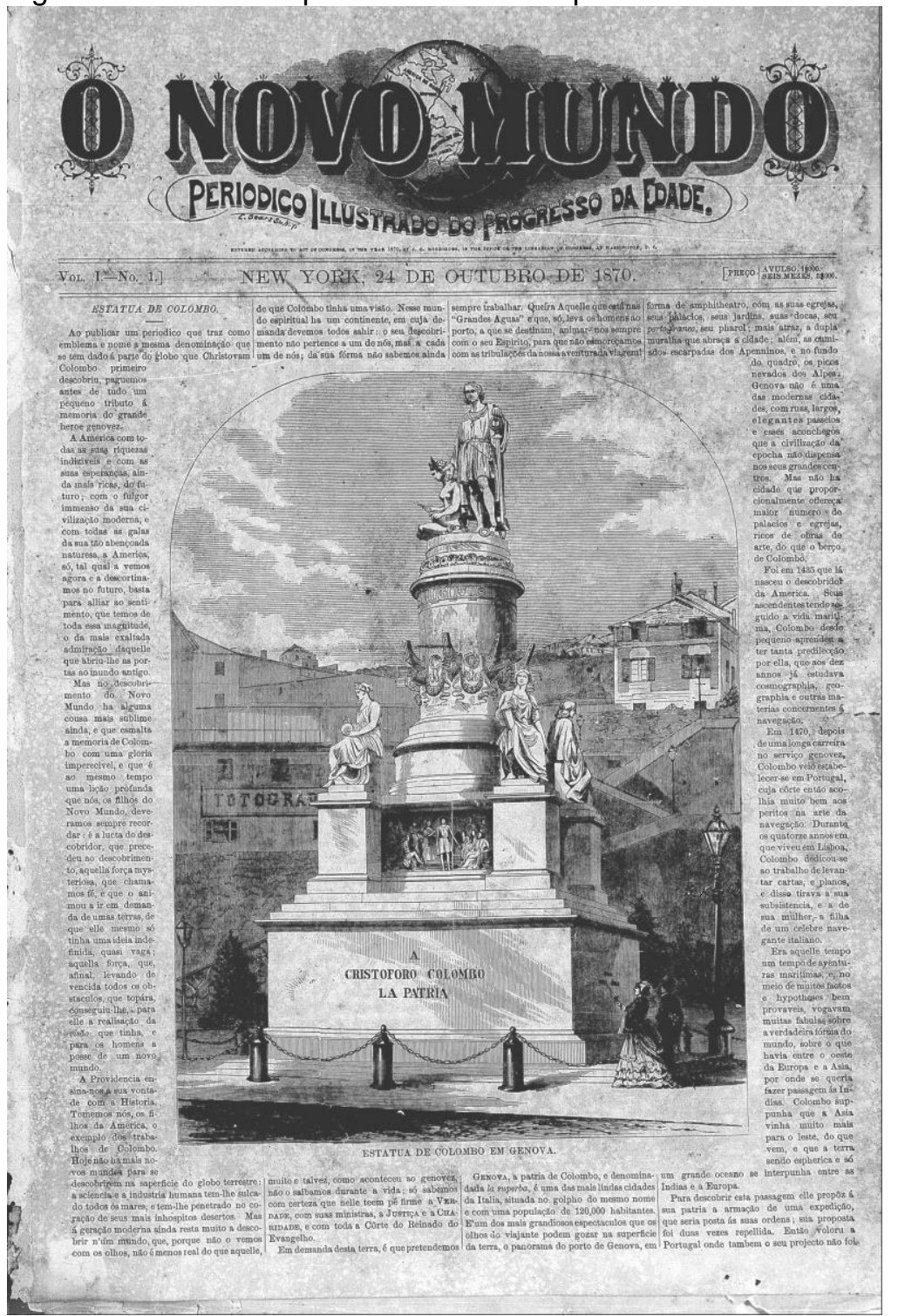

Fonte: Biblioteca Nacional Digital (II, 1, outubro/1870, p.1) 


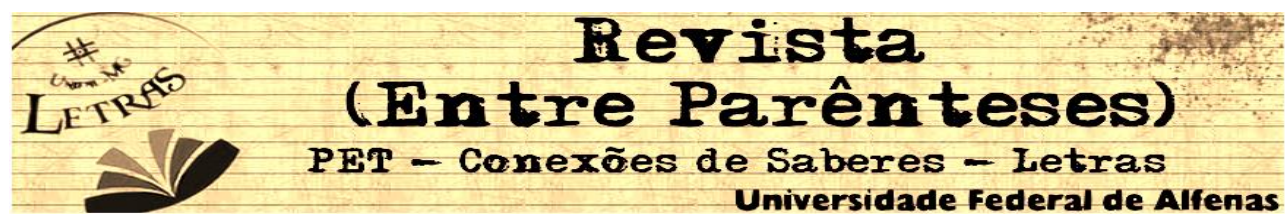

O Novo Mundo foi um jornal liberal, de ideias republicanas, abolicionista, progressista. Escrito do novo mundo para o novo mundo, algo que o afasta do ideal europeu de civilização tão caro às elites brasileiras de então, "contrapondo-se às concepções que viam na França, o velho mundo, o exemplo e o modelo para o Brasil”. (BERGAMINI, 2013, p.11)

Vale ressaltar que o texto machadiano foi escrito sob encomenda, José Carlos Rodrigues convida Machado de Assis para escrever um artigo sobre o estado da literatura brasileira da época, por isso a palavra notícia no título do ensaio. Esse convite é feito por meio de cartas trocadas entre o escritor brasileiro e o proprietário do jornal. Na época, Machado acabava de publicar seu romance Ressurreição, sobre a qual mais tarde José Rodrigues escreverá uma crítica em seu jornal:

New York, 22 de setembro de 1872

Ilustríssimo Senhor Machado de Assis

Dou-lhe os parabéns pelo brilhante sucesso da sua Ressurreição, que li há dias e que hei de dizer por extenso o que penso nalgum dos próximos números do Novo Mundo.

Este jornal (que tem chegado agora ao $3^{\circ}$ ano a salvamento) precisa de um bom estudo sobre o caráter geral da literatura brasileira contemporânea, criticando suas boas e más tendências, no aspecto literário e moral: em estudo que, sendo traduzido e publicado aqui em inglês, dê uma boa ideia da qualidade da fazenda literária que lá fabricamos, e da escola ou escolas do processo da fabricação. Como sabe, se não escrevo bem sobre nenhum assunto, muito menos sobre literatura; nem tenho tempo de ir agora estudá-la. Quererá o amigo escrever sobre isso?- Não posso dizer-lhe de antemão quanto Ihe pagarei pelo trabalho; mas digo-lhe que desejo muito ter esse artigo e hei de retribuir-lhe o melhor que puder, regulando-me sempre pela qualidade, não pelo tamanho do escrito. Talvez possamos fazer algum arranjo efetivo para trabalhos deste gênero. Em todo caso estimaria ter uma ideia de quanto deseja receber por seu trabalho.

(...)

Desejando-lhe muita saúde e as mais bênçãos cristãs, fico

De Vossa Senhoria

patrício e criado obrigado

J. C. Rodrigues

(ASSIS, 2009, p.78-79) 


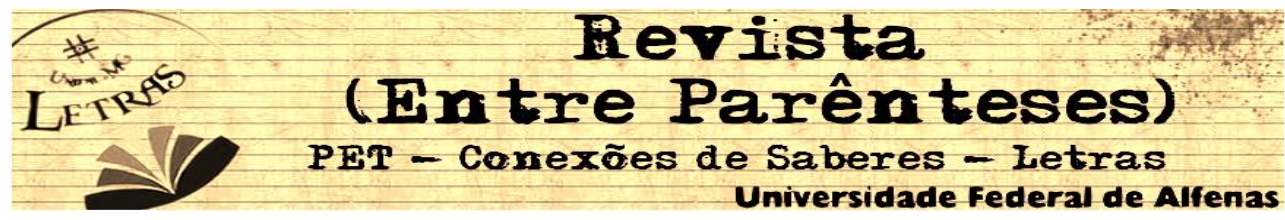

Conforme prometido, José Carlos Rodrigues escreve um artigo a respeito do romance machadiano, Ressurreição. Em resposta a Rodrigues, Machado começa agradecendo aos elogios e as críticas feitas pelo proprietário do jornal e mais adiante mostra que $o$ artigo encomendado já está pronto:

Rio de Janeiro, 25 de janeiro de 1873.

Ilustríssimo Senhor Doutor José Carlos Rodrigues

Aperto-lhes mui agradecidamente as mãos pelo seu artigo do Novo Mundo a respeito do meu romance. E não só agradeço as expressões amáveis com que me tratou, mas também os reparos que me fez. Vejo que leu meu livro com olhos de crítico, e não hesitou em dizer o que pensa de alguns pontos, o que é para mim mais lisonjeiro que tudo. Escrevera-Ihe eu mais longamente desta vez, se não fora tanta coisa que me absorveu hoje o tempo e o espírito. Entretanto não deixarei de lhe dizer desde já que as censuras relativas a algumas passagens menos recatadas são para mim sobremodo salutares. Aborreço a literatura de escândalo, e busquei evitar esse escolho no meu livro. Se alguma coisa me escapou, espero emendar-me na próxima composição.

O nosso artigo está pronto há um mês. Guardei-me para dar-lhe hoje uma última demão; mas tão complicado e cheio foi o dia para mim, que prefiro demorá-lo para o seguinte vapor. Não o faria se se tratasse de uma correspondência regular como costumo fazer para a Europa; trata-se, porém, de um trabalho que, ainda retardado um mês não perde a oportunidade. (...)

Seu amigo, patrício admirador Machado de Assis

(ASSIS, 2009, p.83)

Quando Machado de Assis escreve este artigo para o Jornal O Novo Mundo, no Brasil, no contexto político-social, eram frequentes as discussões acerca da construção da identidade nacional. De acordo com Mônica Asciutti, "o programa literário romântico passava por uma avaliação crítica de escritores e intelectuais, que questionavam, por exemplo, a presença da cultura francesa no Brasil" (2010, p.11). E é exatamente, com esse pano de fundo que o escritor de Helena publica seu ensaio.

Sendo o espaço de circulação Nova lorque, distante dos olhos europeus, pode-se falar em entre-lugar e por esse motivo trazer à luz desse trabalho as 


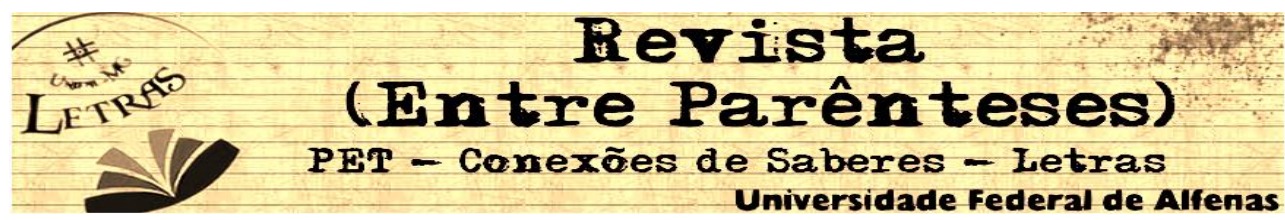

considerações de Silviano Santiago. Machado de Assis pretendia apontar uma nova saída para a literatura brasileira. Além do título de seu artigo, o local de publicação favorece e abriga essa ideia. Desviar o foco da Europa, longe dos modelos franceses e da dependência de Portugal, projeto de uma literatura independente no Brasil, assim como Santiago pretendia inverter os valores do discurso latinoamericano no confronto com o europeu, colocando em evidência a América Latina, no caso de Machado de Assis, mas especificamente o Brasil. A partir disso, publicar nos Estados Unidos e não na Europa já mostra uma reação diante daquele modelo eurocentrico seguido até então. Ou seja, o local de publicação revela já esse entrelugar contido na proposta machadiana para a literatura brasileira naquele momento.

Machado de Assis era também um entusiasta e admirador da cultura europeia no geral, mas uma opnião não exclui a outra, ele acreditava no progresso do Brasil e participava para que isso acontecesse. Silvia Maria de Azevedo destaca exatamente esse ponto de vista machadiano na introdução de seu livro Machado de Assis: crítica literária e textos diversos. Nesse texto ela recupera a saudação que Machado de Assis faz em nome da Academia Brasileira de Letras ao historiador italiano Guglielmo Ferrero em visita ao Brasil durante o mês de outubro em 1907:

Agora que ides deixar-nos levareis à Itália, e por ela ao resto do mundo europeu a notícia do nosso grande entusiasmo. Creio que levareis mais. O que o Brasil revelou da sua crescente prosperidade ao eminente historiador de Roma ter-Ihe-á mostrado que este pedaço de América não desmente a nobreza da estirpe latina e crê no papel que de futuro lhe cabe. (ASSIS, 2013, p. 18)

É também com essa ideia que, anos antes, em 1873, finaliza seu ensaio em Nova lorque, acreditando no "certíssimo futuro" da literatura brasileira, ideia essa que sempre acompanha seus escritos. Ainda em 1861, em uma crônica para o Diário do Rio de Janeiro, na série "Comentários da Semana", Machado novamente trata do aspecto nacional, desta vez com relação à música, mostrando sua preocupação com o futuro da arte brasileira: "Enquanto louvamos a arte estrangeira não esqueçamos a arte nacional.” (ASSIS, 2008, p.73). Nesse caso, o escritor está 


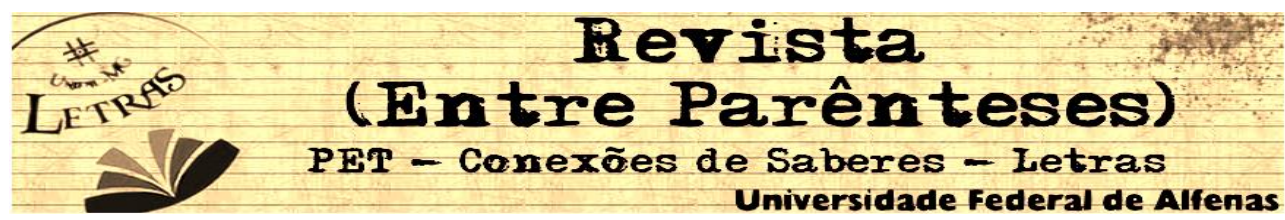

se referindo a ópera cômica francesa, que ocupava as páginas da crônica machadiana com a representação de Domino Noir.

Percebe-se então, a preocupação do escritor com relação à arte nacional em todas as esferas, de modo que o texto de 1873 parece funcionar como uma carta programa para essa independência com relação à literatura, uma proposta para marcar o lugar da literatura brasileira, longe de doutrinas absolutas que a embopreçam, longe das amarras europeias, de modo que não publicar esse ensaio em terras do velho mundo assinala já um grito de independência.

Passemos agora para as diretrizes que marcam no decorrer do ensaio o entre-lugar proposto por Machado de Assis.

\section{Entre o índio e os modelos europeus}

Quando Machado de Assis publica esse ensaio sua carreira de crítico literário já estava reconhecida, José de Alencar já havia Ihe enviado aquela carta aberta para que fosse o Virgílio de Castro Alves no "ínvio caminho da vida literária" (ASSIS, 2013, p.336). Dizia José de Alencar que nenhum dos escritoes modernos tinha os mesmos títulos, para apresentar ao público fluminense o poeta baiano:

O Sr. Foi o único de nossos modernos escritores que se dedicou à cultura dessa difícil ciência, que se chama crítica. Uma porção do talento que recebeu da natureza, em vez de aproveitá-lo em criações próprias, não duvidou aplicá-lo a formar o gosto e desenvolver a literatura pátria" (ALENCAR, 2013, p. 336)

Trilhava, dessa maneira, o caminho da consagração. Sílvia Maria de Azevedo intitula a fase em que escreveu "Instinto de Nacionalidade" como "O triunfo do crítico literário". Nesse sentido, nota-se o alcance da voz machadiana naquele momento, para fazer um balanço da literatura brasileira da época propondo novas saídas.

Machado de Assis desde 1859 vinha se dedicando a essa ciência de grande dificuldade como mencionara José Alencar, carreira esta que nunca será 


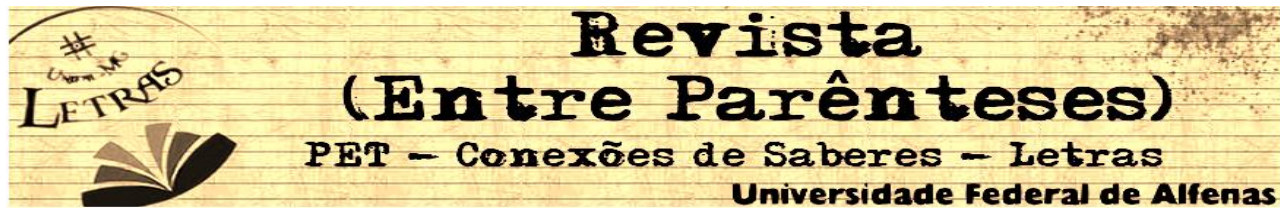

abandonada, entretanto, seus primeiros textos de crítica literária na imprensa foi exercendo a função de folhetinista:

A partir de então passa a ocupar, paulatinamente, um lugar que, poucos antes dele com exceção, talvez, de Macedo Soares, haviam frequentado de forma constate e sistemática. Para tanto, a carreira de Machado como crítico teve início como folhetinista, como também era chamado o cronista no decorrer do século XIX. (AZEVEDO, 2013, p.15)

Para o escritor de Helena a crítica tinha fundamental importância para a formação de uma literatura nacional, de forma que acreditava na crítica como missão. Em seu texto "Ideal do crítico" escrito em 1865, Machado de Assis deixa claro que uma grande literatura dependeria da crítica. Também preocupado com o desenvolvimento de uma literatura pátria escreve este ensaio de 1873, assunto que sempre o preocupara.

"Instinto de Nacionalidade" mostra a insatisfação de Machado de Assis com a forma como o elemento nacional vinha sendo abordado na literatura brasileira, que empenhada em criar uma literatura pátria depois da independência política em relação a Portugal, parecia forçar nos excessos. De acordo com João Alexandre Barbosa (1990, p.43) a crítica brasileira da época estava preocupada em buscar a nacionalidade na literatura e até os anos setenta ela é o exercício da interpretação acerca da medida em que a literatura responde à evolução histórica. Aponta que era natural desde o início das reflexões críticas no Brasil o debate ser entorno da busca de uma diferença com relação à Europa e, de certo modo, pela identidade nacional, o que ele chama de paixão interpretativa, a busca pela nacionalidade, ocorrendo a prevalência da história sobre a literatura. História e literatura não eram vistas sempre juntas e a função da crítica era de indicar a relação de necessidade entre uma e outra, e as obras literárias eram percebidas como reflexo ou resultado do desenvolvimento histórico.

Deste modo, a insatisfação de Machado de Assis com a busca dessa nacionalidade, o faz escrever "Instinto de Nacionalidade", que de acordo com João Alexandre Barbosa, conseguiu fisgar de modo admirável o cerne do problema, recusando "a servidão da literatura à história, enquanto mecanismo simples e puro 


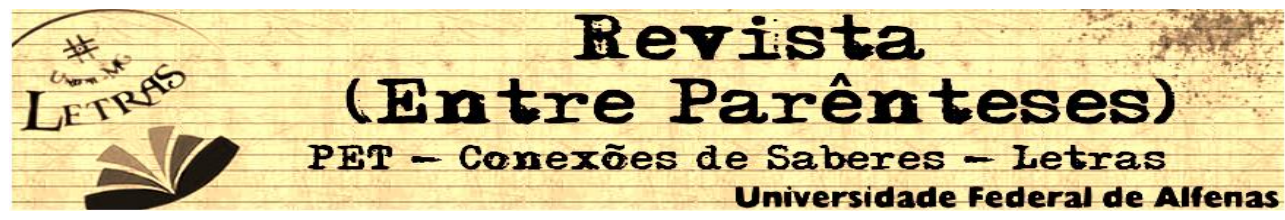

reflexo" (BARBOSA, 1990, p 43). Mas Machado de Assis não é o único, muitos outros artistas literários, a partir da segunda metade do século XIX, formularam a mesma indagação. Baudelaire, por exemplo, também buscava "traduzir, nos interstícios pessoais de seus textos, as articulações entre literatura e história". (BARBOSA, 1990, p.43)

O escritor brasileiro nega o fato de que uma literatura independente, uma literatura nacional deva tratar somente de assuntos locais. Como já dito, no Brasil dessa época, as expressões de nacionalismo e o nacional na literatura ganham força, exaltava-se "elementos como a cor local e incursão no regionalismo como formas preferenciais para expressar o nacional" (ASCIUTTI, p.89), de modo que, com esse ensaio o escritor contesta os alicerces constitutivos da literatura brasileira proposto pelos românticos. Sabe-se que Machado de Assis tinha uma admiração não cega pelo romantismo, alguns anos depois em "A nova geração" ele condena os excessos da escola hugoísta liderada por Sílvio Romero (CALLIPO, 2006), escola esta "que buscava os efeitos em certos meios puramente mecânicos" e aconselhou a evitar aquele condor que, "à força de voar em tantas estrofes, há doze anos, acabou por cair no chão, onde foi apanhado e empalhado" (ASSIS, 2013, 525)

Mesmo questionando tais aspectos da literatura, Machado reconhece que uma literatura nascente deve alimentar-se de assuntos oferecidos por sua região, mas o material literário deve exigir do escritor "certo sentimento íntimo, que o torne homem do seu tempo e de seu país, ainda quando trate de assuntos remotos no tempo e no espaço". (ASSIS, 2013, p. 433)

Nesse sentido, é certo que para o escritor fluminense a figura do índio não é um patrimônio exclusivo da literatura brasileira, por esse motivo uma literatura independente não seria feita essencialmente de costumes indígenas. "Erro seria constituí-lo em exclusivo patrimônio da literatura brasileira; erro igual fora certamente a sua absoluta exclusão". (ASSIS, 2013, p.431).

Com tudo isso, além do contexto de publicação abrigar a ideia de entrelugar, o escritor também parece propor um entre-lugar para a literatura brasileira no correr da sua pena, uma saída, longe de doutrinas tão absolutas, um equilíbrio, uma justa medida, assim como Silviano Santiago aponta o lugar do discurso latino- 


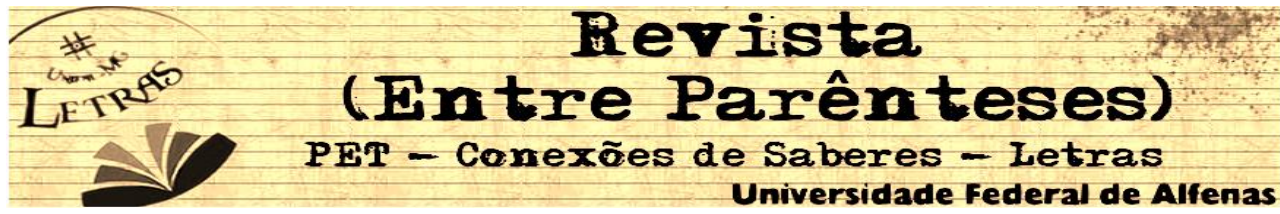

americano anos mais tarde, mostrando o deslocamento e a visibilidade de uma America Latina independente. Dessa maneira o termo e a proposta de Silviano parecem aplicar-se perfeitamente na proposta machadiana.

Mudam-se os tempos e os escritores, mas o lugar do discurso literário latinoamericano parece sofrer poucas mudanças, permanece nesse entre-lugar. Para Machado a literatura nacional tão almejada pelos brasileiros não está no elemento indígena, tão pouco na negação dele, entre o nacional e o universal, entre a ruptura e o diálogo com a literatura europeia, entre o índio e o homem colonizado, entre a grandeza e a simplicidade, entre a Europa e a América.

Machado de Assis e Silviano Santiago aspiram uma independência da literatura, uma ruptura com os modelos copiosos europeus, ou seja, o estabelecimento de um diálogo e não uma absorção passiva daquilo que lhe é alheio. Em "Instinto de Nacionalidade", o escritor parece deixar claro essa sua opinião ao tratar da língua:

Não há dúvida que as línguas se aumentam e alteram com o tempo e as necessidades dos usos e costumes. Querer que a nossa pare no século de 500 é um erro igual ao de afirmar que a sua transplantação para a América não Ihe inseriu riquezas novas. (ASSIS, 2013, p.440)

Cada tempo tem o seu estilo. Mas estudar-Ihes as formas mais apuradas da linguagem, desentranhar deles mil riquezas que, à força de velhas, se fazem novas - não me parece que se deva desprezar. Nem tudo tinham os antigos, nem tudo temos os modernos; com os haveres de uns e outros é que se enriquece o pecúlio comum. (ASSIS, 2013, p.441)

Os dois escritores têm os olhares voltados para a América, na renúncia da "situação de colônia", em busca da independência da literatura, Silviano assinala, por exemplo, a negação daquele discurso de uma America Latina "sorridente e feliz" e aponta a não ingenuidade dos escritores latino-americanos, destacando sua capacidade:

A leitura fácil dá razão às forças neocolonialistas que insistem no fato de que o país se encontra na situação de colônia pela preguiça de seus habitantes. O escritor latino-americano nos ensina que é preciso liberar a imagem de uma América Latina sorridente e feliz, o 


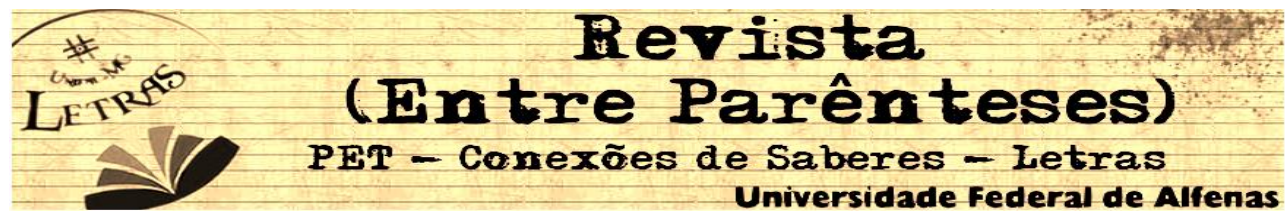

carnaval e a fiesta, colônia de férias para o turismo cultural. (SANTIAGO, 2000, p.26)

Com esses olhares também dirigidos à América, vendo a imagem do continente americano enquanto matéria poética, é que Machado de Assis escreve uma coletânea de poemas intitulados Americanas e realiza aquilo que propõem em "Instinto de Nacionalidade".

\section{Saída: Americanas}

Dois anos depois, em 1875, Machado de Assis em seu livro de poemas intitulado Americanas parte daquela temática cara aos românticos e discutida em seu texto de 1873, o indianismo, diferenciando-se quanto ao tratamento do tema e apresenta aquilo que propusera em seu ensaio. Tem-se a sensação de que o ensaio já era uma advertência prévia do tipo de atividade poética que o autor pretendia realizar:

é importante perceber como ele se lança desse discurso em seu projeto poético, já que o intuito não é de fato manifestar-se enquanto poeta nacional em sua especificidade programática, mas apresentar uma nova possibilidade de execução artística indianista e, quiçá, revelar este "sentimento íntimo" ao qual se refere" (GRANDOLPHO, 2014, p. 56)

Vale ressaltar que os poemas de Americanas não tratam somente da figura do índio, na própria "advertencia”, escrita por Machado de Assis, ele nos antecipa o tema do livro, alertando que nem toda a temática diz respeito "aos nossos aborígenes" e mostra o poema "Sabina" e o poema "A Cristã Nova" como poemas que tematizam a ação passada no "centro da civilização", algo que aponta para a diversidade temática de Americanas, que também conta com dois poemas-elegias: “José Bonifácio" e "Gonçalves Dias". Essa diversidade temática também mostra a naturalidade comentada por Machado ao tratar do argumento indígena, não tratando o índio como única temática para uma literatura nacional. Ele Reconhece, dessa maneira, o indianismo tanto como matéria poética brasileira quanto universal, ou seja, mesmo produzindo uma literatura com base no aspecto local ele conseguia ser 


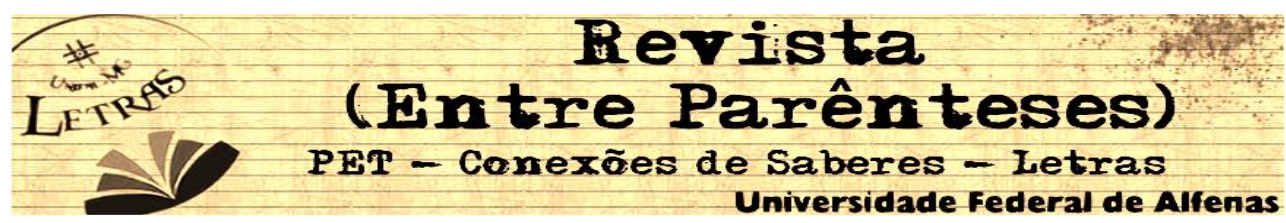

universal, talvez porque tenha se valido da essência tão discutida em seu ensaio: sentimento íntimo.

Com a figura do homem civilizado em seus poemas, Machado toca em um dos pontos que tratou em seu texto: Iracema, de José de Alencar, obra pela qual tem grande admiração e considera de "singular efeito" enquanto exemplo de literatura brasileira, um livro que entrelaça o "elemento bárbaro com o civilizado" (Assis, 2013, p.431).

Vale ressaltar também que Machado escreve Americanas no final do século $\mathrm{XIX}$, depois do considerando ápice da poesia indianista. Isso mostra uma certa desobrigação com a temática e podemos considerar, então, que o elemento indígena é posto de lado de outros temas para ser apresentado como "um temário comum ao fazer poético de nosso país". (GRANDOLPHO, 2014, p.56).

Além disso, é possivel encontrar em Americanas um diálogo com a literatura estrangeira, como por exemplo, com Dante Alighieri, ou seja, entre o nacional e o universal, conceito que enfatiza em seu texto para a formação de uma literatura pátria. A esse respeito, Marta de Senna destaca a importância do diálogo com a literatura estrangeira para a formação de uma literatura nacional:

defendo a ideia de que o diálogo com a melhor literatura do Ocidente é uma das vias pelas quais o nosso autor se afirma como grande escritor e, por essa via, eleva a produção literária de seu país a um patamar de igualdade com essa literatura. O que, convenhamos, é uma forma inteligentíssima de "nacionalismo." (SENNA, p.79).

Diálogo, diferença, ruptura, transgressão, violência. Para Santiago essas são as palavras do discurso latino-americano em relação aos modelos europeus. Ele propõe que uma literatura para não ser invisível é aquela não copiosa, que mostra a diferença, antropofágica, que dialoga com o outro, contestando o conceito de superioridade.

Não com as mesmas palavras, mas com o mesmo propósito, Machado anos antes percebia já a necessidade dessa absorção não passiva dos modelos europeus, do diálogo, que a formação de uma literatura nacional não poderia partir da copia da literatura europeia, caso contrário seria invisível. 


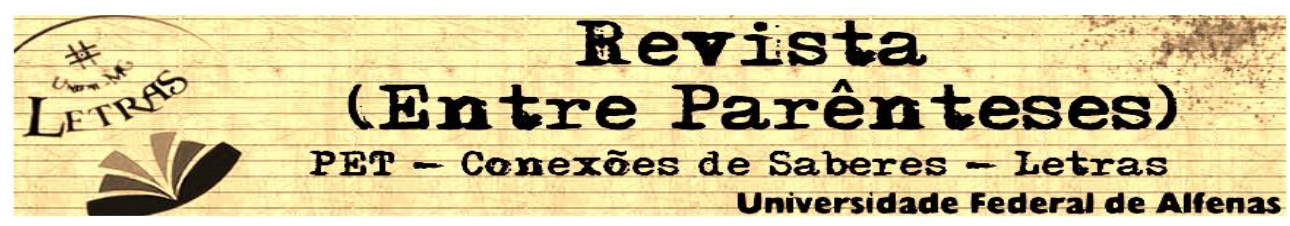

Pode-se dizer então, que Machado de Assis consegue colocar seu livro de poemas nesse entre-lugar e mais tarde toda sua produção buscará esse mesmo espaço.

\section{REFERÊNCIAS}

ASCIUTTI, Mônica Maria Rinaldi. Um lugar para o periódico 0 Novo Mundo. Dissertação de Mestrado. São Paulo: USP, 2010.

AZEVEDO, Sílvia Maria. Introdução. In: ASSIS, Machado de: Crítica literária e textos diversos. Organização Sílvia Maria Azevedo, Adriana Dusilek, Daniela Mantarro Callipo. São Paulo: Editora Unesp, 2013.

ASSIS, Machado. Crítica literária e textos diversos. Organização Sílvia Maria Azevedo, Adriana Dusilek, Daniela Mantarro Callipo. São Paulo: Editora Unesp, 2013.

Correspondência de Machado de Assis: tomo II, 18701889/coordenação e orientação Sergio Paulo Rouanet; reunida, organizada e comentada por Irene Moutinho e Sílvia Eleutério. Rio de Janeiro: ABL, 2009.

Cano. Campinas: Editora da Unicamp, 2008.

Comentários da Semana. Organização Lúcia Granja e Jefferson

BERGAMINI, Atilio. "Instinto de nacionalidade" na imprensa liberal. Machado de Assis em linha. Rio de Janeiro. v. 6, n. 12, p. 15-31, dezembro 2013.

BARBOSA, João Alexandre. Paixão Crítica. In: A leitura do intervalo: ensaios de crítica. Rio de Janeiro: lluminuras, 1990, p.63-75.

CALLIPO, Daniela Mantarro. Rimas de ouro de sândalo: a presença de Victor Hugo nas crônicas de Machado de Assis. Signótica, v. 18, n. 1, p. 17-42, jan./jun. 2006. Disponível em: <http://www.revistas.ufg.br/index.php/sig/article/view/3717/3472> Acesso em: 02/11/2014

GRANDOLPHO, Marina Venâncio. O indianismo em Americanas (1875) de Machado de Assis (Releitura da tradição romântica). Dissertação de mestrado. Universidade Federal de São Carlos, São Carlos, 2014.

SANTIAGO, Silviano. O entre-lugar do discurso latino-americano. In: Uma literatura nos trópicos. São Paulo: Rocco, 2000. 


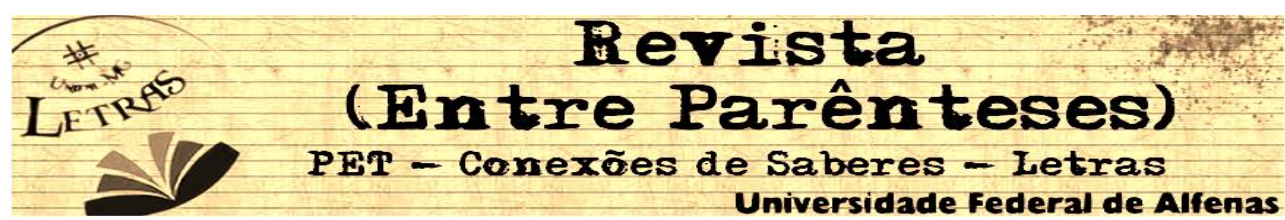

SENNA, Marta de. Machado de Assis: Certo instinto de nacionalidade. Revista da Fundação Casa Rui Barbosa, Ano. 3, n. 3. 2009. Disponível em:

$<$ http://www.casaruibarbosa.gov.br/escritos/numero03/FCRB Escritos 35 Marta d e Senna.pdf> Acesso em: 03/02/2015

\section{Periódicos Consultados}

BIBLIOTECA DIGITAL NACIONAL (Brasil). O Novo Mundo. Disponível em: $<$ http://memoria.bn.br/DocReader/DocReader.aspx?bib=122815\&PagFis=2162\&Pes q=instinto\%20de\%20nacionalidade > Acesso em: 30/04/2015 